Revista Monografias Ambientais - REMOA v. 15, n.1, jan-abr. 2016, p.256-263 Revista do Centro de Ciências Naturais e Exatas - UFSM, Santa Maria, RS e-ISSN 22361308 - DOI:10.5902/22361308

\title{
SEGREGAÇÃO SOCIOESPACIAL: OS IMPACTOS DAS DESIGUALDADES SOCIAIS FRENTE A FORMAÇÃO E OCUPAÇÃO DO ESPAÇO URBANO
}

\author{
Segregation sociospatial: the impact of social inequality face to training and occupation of urban \\ space \\ Manoel Mariano Neto da Silva, Daniela Freitas de Lima, \\ Almir Mariano de Sousa Junior, Carla Caroline Alves Carvalho \\ Universidade Federal Rural do Semi-Árido (UFERSA), Pau dos Ferros, RN, Brasil
}

Resumo

Pau dos Ferros/RN é uma cidade de grande importância na região do Alto Oeste, uma vez que é referência para as cidades circunvizinhas. Partindo desse contexto, as áreas centrais apresentam custos onerosos, o que torna a aquisição e ocupação inviável pela população carente. Mediante tais discussões, esta pesquisa tem por finalidade analisar os impactos da segregação socioespacial no Bairro Manoel Deodato. Na execução da pesquisa, realizaram-se estudos bibliográficos acerca da formação e ocupação do espaço urbano no Brasil, discutiu-se a segregação socioespacial como uma problemática urbana e social. Posteriormente, foi executada uma pesquisa documental junto ao Cartório de Imóveis e a Prefeitura Municipal. Realizaramse visitas in loco e registros fotográficos do assentamento. Verifica-se que a área teve o processo de ocupação iniciado por volta de 1899. Inicialmente, as residências em sua totalidade eram construídas as margens do Rio Apodi-Mossoró. Outra questão que remete a ocupação desse assentamento é o déficit habitacional, visto que a princípio a maioria das casas eram de taipa ou barracos improvisados. Assim, o Bairro Manoel Deodato possui marcas expressivas da segregação socioespacial, visto que a população residente apresenta vulnerabilidade econômica, há uma carência de infraestrutura e equipamentos urbanos, além da existência de riscos ambientais.

Palavras-chave: Segregação Socioespacial, Bairro Manoel Deodato, Vulnerabilidade Social.

Abstract

Pau dos Ferros/RN is a city of great importance in the Upper West Region, since it is a reference to the cities. From this context, the central areas are burdensome costs, which makes the acquisition and occupation unaffordable by the poor population. Through such discussions, this research aims to analyze the socio-spatial segregation of impacts in the neighborhood Manoel Deodato. In implementing the research, there were bibliographical studies about the formation and occupation of urban space in Brazil, discussed the socio-spatial segregation as an urban and social problems. Later, a documentary research by the Office of Real Estate and the Municipality was performed. There were on-site visits and photographic records of the settlement. It appears that the area had the occupation process started around 1899. Initially, the residences were built in its entirety the banks of Apodi-Mossoró River. Another issue that refers to occupation of this settlement is the housing deficit since the beginning most of the houses were made of mud shacks or improvised. Thus, the district Manoel Deodato has significant brands of socio-spatial segregation, as the resident population has economic vulnerability, there is a lack of infrastructure and urban facilities, in addition to the existence of environmental risks.

Keywords: Socio-Spatial segregation, neighborhood Manoel Deodato, Social Vulnerability. 


\section{Introdução}

Os centros urbanos brasileiros sofreram significativas modificações durante o século XX em decorrência da industrialização. Como reflexo da intensificação das atividades industriais, a população urbana cresceu expressivamente, visto que de acordo com o Instituto de Pesquisa Aplicada - IPEA (2011) e Instituto Brasileiro de Geografia e Estatística - IBGE (2010), entre 1950 e 2010, a população urbana brasileira cresceu de 52 para 160 milhões de habitantes.

Devido a rápida urbanização, uma série de problemas foram desencadeados, pois as cidades não estavam preparadas para acomodar uma massa populacional tão volumosa e como resposta, os residentes na zona urbana ficaram expostos a condições precárias quanto ao que se refere à moradia, segurança e saúde.

A partir do surgimento de novos centros urbanos, deu-se início a uma nova dinâmica urbanoregional, uma vez que dentro desse contexto estão as cidades médias, que atuam como um vínculo entre as pequenas e grandes cidades. Mas, as desigualdades sociais relacionadas à fragmentação e formação do espaço também apresentam consequências negativas para o desenvolvimento social e urbano desses centros.

Nesse sentido, Pau dos Ferros/RN se caracteriza como uma cidade intermediária de grande importância comercial na região do Alto Oeste, uma vez que é referência para as cidades circunvizinhas, interagindo ainda com as cidades de outros estados. Além dos aspectos econômicos, há também a formação do polo educacional de ensino superior, que vem a contribuir para o aumento da sua importância no cenário regional. Todos esses fatores favorecem o crescimento urbano, que por sua vez promove a especulação imobiliária. Partindo desse contexto, as áreas centrais passam a apresentar custos muito onerosos, o que torna a aquisição e ocupação inviável pela população em estado de vulnerabilidade social.

Mediante tais discussões, esta pesquisa tem por finalidade analisar os impactos da segregação socioespacial no Bairro Manoel Deodato, localizado na Cidade de Pau dos Ferros/RN. Para tanto, fazse necessário estudar o histórico de ocupação desta área, bem como consultar as condições jurídicofundiárias, além de abordar a infraestrutura e equipamentos urbanos presentes no assentamento.

\section{Pau dos Ferros/RN}

A Cidade de Pau dos Ferros/RN de acordo com o Instituto Brasileiro de Geografia e Estatística IBGE (2010) possui aproximadamente 30 mil habitantes e se encontra localizada na Mesorregião do Alto Oeste Potiguar. Essa cidade originou-se a partir do comércio, primeiramente pela expansão da pecuária bovina e logo após, surgiu a produção algodoeira. Atualmente, Pau dos Ferros/RN detém significativa representatividade regional devido a produção de emprego e renda a partir da prestação de serviços e das atividades comerciais locais, estabelecendo dessa forma, importantes relações com as cidades circunvizinhas.

De acordo com as Regiões de Influência das Cidades - REGIC (2007), Pau dos Ferros/RN é classificada como Centro Sub-regional, um nível de grande importância para a rede urbana nordestina interiorizada, visto que esses centros assumem funções de intermediação entre os grandes centros urbanos e as pequenas cidades, em outras palavras, podemos classificá-la como uma cidade média ou intermediária. De acordo com Dantas (2011) um fator que contribui para essa classificação é a localização no meio do antigo triângulo das capitais regionais (Mossoró-RN, Campina Grande-PB e Juazeiro do Norte-CE), os quais eram denominados de polos de crescimento.

Nesse contexto, de acordo com Carvalho e Barbosa (2014), Pau dos Ferros/RN é considerado como grande polo educacional existindo uma participação significativa do setor público quando trata da implementação de cursos de nível superior, com a implementação da Universidade Federal Rural do 
Semi-Árido (UFERSA), Universidade Estadual do Rio Grande do Norte (UERN), e médio integralizado com técnico no Instituto Federal do Rio Grande do Norte (IFRN), existindo também as universidade privadas, Facep e Anhaguera. Todos esses fatores colaboram para que essa cidade se apresente como uma cidade média.

Segundo Dantas e Clementino (2013), as cidades médias continuam a ser valorizadas como fator de equilíbrio para as redes e hierarquias urbanas, bem como por exercer as funções de relação e intermediação com as grandes e pequenas cidades e com o meio rural. Para os autores, o papel de articulação e intermediação são fundamentais para a implantação, desenvolvimento e a expansão dos corredores de transporte e comunicações.

Diante disso, Carvalho e Barbosa (2014) afirmam que a especulação imobiliária em Pau dos Ferros/RN também é uma realidade, pois com o crescimento da cidade surge a especulação e aumentos consideráveis nos preços dos imóveis próximos ou presentes no centro urbano. Em contrapartida, tal fator se apresenta como um forte agravante quanto a fragmentação do espaço e aceleramento da segregação socioespacial, visto que as áreas periféricas são menos valorizadas devido à falta de estrutura e serviços urbanos, e consequentemente, são ocupadas pela população de baixa renda.

\section{Formação e ocupação do espaço urbano brasileiro}

O crescimento urbano no Brasil se deu principalmente a partir da segunda metade do século $\mathrm{XX}$, em decorrência do desenvolvimento do setor industrial. Conforme o IBGE, o percentual de habitantes que residiam na zona urbana brasileira em 1950 era de 30\%, desse modo, verifica-se que a maior parcela da população concentrava-se na zona rural. Já em 2010, o percentual chegou aos $84 \%$. Em contrapartida, a estrutura urbana brasileira não estava preparada para comportar um montante populacional tão elevando, e devido a tal fator a população socialmente vulnerável passou a ocupar as periferias das cidades.

Esse processo não ocorreu de forma igualitária no cenário nacional, visto que as regiões sul e sudeste se desenvolveram mais rapidamente devido aos altos investimentos no setor econômico e aos benefícios políticos. Como resposta, seus índices de crescimento urbano em alguns estados chegaram a atingir 95\%, enquanto que nas regiões norte e nordeste a maior taxa de crescimento deste setor foi de $55 \%$. Essas desigualdades na dinâmica urbana e regional tem um potencial altamente danoso. Pois além dos contrastes sociais, as áreas menos favorecidas são condenadas a estagnação do crescimento nos mais diversos âmbitos.

A partir de todos esses aspectos surge o déficit habitacional, que no Brasil, de acordo com o IPEA (2013) no ano de 2007 a taxa era de 10\%. Já em 2012, houve uma redução de 1,47\%, chegando ao percentual de $8,53 \%$. A queda deste índice evidencia que o país está passando por um período de evolução quanto ao acesso à moradia. Porém, esse avanço não ocorreu de maneira uniforme em todo território brasileiro. As regiões sul e sudeste apresentam os valores mais baixos do país, mas em decorrência da grande massa populacional essas regiões possuem aproximadamente $50 \%$ do déficit absoluto. Quanto às demais regiões, verifica-se que o norte apresenta déficit de 536 mil domicílios, na região nordeste esse valor chega a 1,61 milhões e no centro-oeste 420 mil.

Pelo fato da maior parcela da população afetada pela ausência de moradias em condições regulares de habitação e saneamento ser caracterizada pelo baixo poder aquisitivo, o déficit habitacional está diretamente ligado à questão da irregularidade urbana. Conforme o IBGE, cerca de 2,2 milhões de domicílios brasileiros se encontram em condições irregulares. Ressalta-se ainda que este problema é presente em praticamente todas as cidades com mais de 500 mil habitantes e que cerca de $39 \%$ das cidades com mais de 20 mil habitantes também possuem assentamentos e outras formas de ocupações irregulares. Neste sentido, Maricato (2013) afirma que a cidade constitui um grande patrimônio histórica e socialmente, mas sua apropriação é desigual em decorrência da renda imobiliária ou localização, pois esses fatores possuem um preço devido aos seus atributos.

Como solução à problemática abordada, verifica-se que a partir de 2009 vários programas sociais foram lançados pelo Governo Federal. Dentre eles, ganham destaque neste âmbito o Programa de 
Aceleração do Crescimento - PAC e o Programa Minha Casa Minha Vida. Assim, é possível afirmar que o incentivo ao acesso a moradia vem a favorecer o desenvolvimento do país tanto nos setores sociais quanto no âmbito econômico.

\section{Segregação socioespacial}

Em decorrência das transformações ocorridas a partir do sistema capitalista, as massas populacionais que até então estavam nas zonas rurais foram direcionadas às cidades, distanciando- se desse modo de suas localidades de origem e em alguns casos, passando a ocupar ambientes com condições insalubres.

No contexto brasileiro, o desenvolvimento industrial e econômico contribuíram para a formação de realidades distintas e junto a todos esses aspectos, surgem as desigualdades sociais, que se mostram mais abrangentes cotidianamente. Assim, todas essas irregularidades podem ser interpretadas como fruto do capitalismo, pois a atividade capitalista produz um desenvolvimento geográfico desigual (HARVEY, 2004).

As marcas deixadas por esse processo começaram a ser amenizadas no início do século no XXI quando políticas públicas e incentivos governamentais passaram a beneficiar as regiões menos favorecidas, contribuindo para a formação de um espaço mais igualitário. A partir desses aspectos, as cidades de porte médio aumentaram, visto que estas tem como principal finalidade reduzir os movimentos migratórios através da ampliação da oferta de empregos e serviços à população do meio rural e das cidades menores no seu entorno (ESTEBAN \& LÓPEZ, 1989). Estas cidades se caracterizaram como médias não somente pela população que ali habita, mas também pelo papel comercial e urbano que elas passaram a exercer. Calvete (2011) pontua que:

[...] a partir do final do século XX e começo do século XXI, se nota uma mudança de direção destes fluxos em direção a cidades médias. Mesmo com o crescimento da economia, as migrações são vistas como fonte de muitos desequilíbrios tanto econômicos quanto sociais, nas regiões de origem e também nas de destino. O aumento populacional econômico das cidades médias leva a uma série de mudanças, reformulando e reestruturando o espaço e as relações dentro delas. (CALVETE, 2011, p. 23).

Entretanto, as cidades intermediárias também são acometidas pela fragmentação do espaço e segregação socioespacial. Esse processo é responsável pela separação da população, visto que as parcelas menos favorecidas e em posição de vulnerabilidade ocupam as áreas periféricas das cidades onde residem, o que contribui para o acesso limitado aos equipamentos urbanos e outros benefícios essenciais para a qualidade de vida. Mediante a tais discussões Corrêa afirma que:

O conceito de segregação apareceu com a Escola de Chicago. Sendo definido como um processo ecológico resultante da competição impessoal que geraria espaços de dominação dos diferentes grupos sociais. Analogamente ao que ocorre no mundo vegetal (Corrêa. 1995. p.59).

Nesse sentido, a segregação socioespacial corresponde à separação espacial em diferentes áreas do território urbano. Desse modo, a segregação do espaço está diretamente atrelada aos aspectos históricos, culturais e econômicos, o que pode ser intensificado devido ao fato das massas populacionais que se caracterizam como vítimas desse processo não possuírem pleno acesso às ferramentas capazes de contornar essa realidade, pois de acordo com Barreira (2014) os indivíduos não têm possibilidades inteiramente livres de escolher suas trajetórias de vida.

Em decorrência da segregação socioespacial, ocorre a divisão de classes sociais, bem como e marginalização dos mais carentes, o que impulsiona a elevação dos índices de desigualdades. Em contrapartida, vários caminhos apontam para a solução dessa problemática, dentre eles, a intensificação das políticas habitacionais e políticas públicas que atuam de forma direta na formação do espaço urbano. Mas, qualquer mudança que se queira fazer, no sentindo de mudança social deve 
considerar a grande complexidade de experiências, visões de mundo e entendimento de todos os processos históricos que fazem parte do dia a dia das pessoas e do lugar (BARREIRA, 2014. p.08).

\section{Metodologia}

Conforme Gil (2007), a presente pesquisa se caracteriza como um estudo de caso, pois buscamos explorar situações reais cujos limites não estão claramente definidos, bem como preservar o caráter unitário do meio estudado e descrever a situação do contexto no qual está sendo realizada a investigação.

Assim, o estudo foi conduzido no Bairro Manoel Deodato, localizado na Cidade de Pau dos Ferros/RN. Durante a sua execução, foram realizados estudos bibliográficos acerca da formação e ocupação do espaço urbano no Brasil, onde foram abordados o IBGE e o IPEA; foi também discutida a segregação socioespacial como uma problemática urbana e social, na qual Calvete (2004), Harvey (2005) e Alencar (2014) foram utilizados como aporte teórico; por conseguinte, abordou-se Pau dos Ferros/RN, sendo Carvalho e Barbosa (2014) o suporte bibliográfico.

Posteriormente, foi executada uma pesquisa documental junto ao Cartório de Imóveis e a Prefeitura Municipal, o que possibilitou analisar a situação jurídico- fundiária do assentamento em questão, bem como o acesso às características socioeconômicas da população ocupante. Além disso, realizaram-se visitas in loco e registros fotográficos do assentamento.

\section{Resultados e Discussões}

O Bairro Manoel Deodato teve o processo de ocupação iniciado por volta de 1899, por famílias vindas das cidades circunvizinhas. Inicialmente, devido a vulnerabilidade da população residente na área, as residências em sua totalidade eram construídas as margens do Rio Apodi-Mossoró, o que se expunha como uma problemática por muitos anos devido aos alagamentos ocorridos nos períodos chuvosos. A Figura 01 apresenta a localização desse assentamento na cidade de Pau dos Ferros/RN:

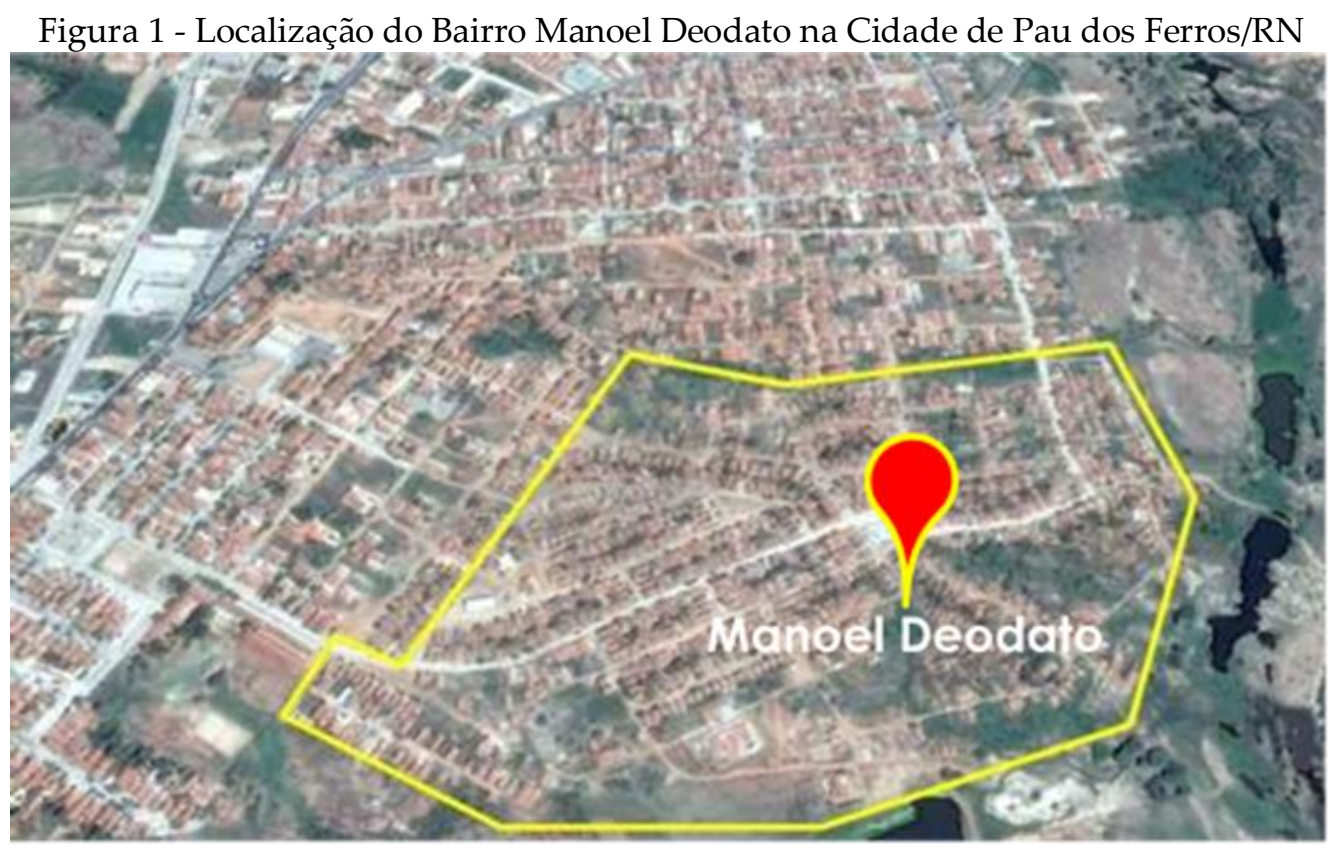

Fonte: Google Earth, adaptada.

Outra questão que também remete aos primórdios da ocupação desse assentamento é o déficit habitacional, visto que a princípio a maioria das casas eram de taipa ou barracos improvisados. $\mathrm{Na}$ busca por soluções para esses problemas, o poder público direcionou parte da população para outros 
bairros, mas devido a entrada de novos moradores, a área se consolidou, e atualmente, de acordo com o Cadastro Único Municipal, abriga 787 famílias.

Todas as problemáticas já citadas apontam para uma deficiência que se iniciou com a ocupação irregular da população e se intensificou devido a atuação ineficiente do poder público frente ao planejamento urbano. Devido aos riscos apresentados pela área à população, pode-se afirmar que o processo de ocupação do assentamento está em desacordo com a Lei 12.688/2012, que afirma que o Plano Nacional de Defesa Civil deve integrar-se às políticas de ordenamento territorial e desenvolvimento urbano, a fim de atingir um planejamento com base em estudos sobre áreas de risco e incidência de desastres no território nacional.

Quanto à infraestrutura e equipamentos urbanos implantados, o Bairro é parcialmente pavimentado e possui coleta do esgoto doméstico, mas esse serviço não beneficia toda população. Além disso, há coleta de lixo, que não ocorre em todas as ruas devido às fragilidades do sistema viário. Verificamos também parte das moradias não possuem acesso direto a rede elétrica oficial, bem como a presença de uma creche e uma quadra de esportes. A Figura 02 mostra o destino do esgoto doméstico e a coleta de lixo no Bairro Manoel Deodato:

Figura 2 - Coleta de resíduos sólidos e ausência de tratamento dos efluentes domésticos no Bairro

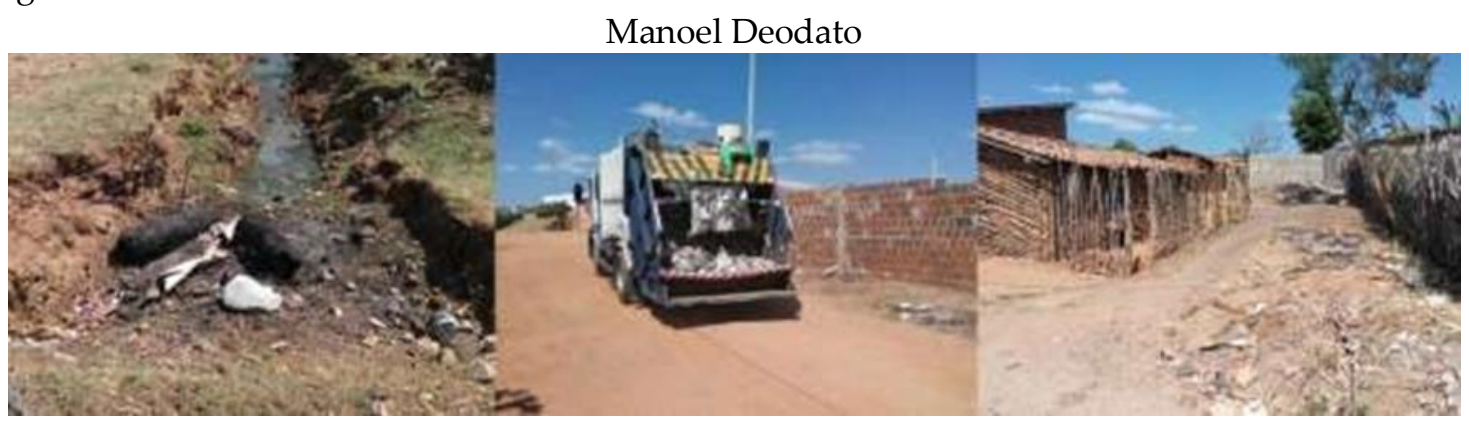

Fonte: Pesquisa, 2015.

A ausência de pavimentação, bem como a precariedade do sistema viário e do saneamento básico, juntamente com a ocupação de uma área de risco são frutos do processo de segregação socioespacial, visto que tais fatores decorrem da periferização dos centros urbanos e da consequente desvalorização e ocupação desse espaço pela população carente.

As problemáticas referentes ao Manoel Deodato se estendem a questão jurídico- fundiária, pois a ocupação mesmo ocorrendo de forma pacífica remete a um processo de invasão de propriedade pública, uma vez que a área ocupada pertence a Data Norte/RN. Tal fator expõe a população à insegurança habitacional, visto que a área pode passar por processos de desapropriações, o que deixaria muitas famílias desabrigadas. Nesse contexto, apesar do direito à moradia ser constitucional e se configurar como um bem essencial para o desenvolvimento, este não é cumprido, o que expõe os residentes da área a vulnerabilidades mais complexas.

O déficit habitacional ainda é muito presente nesta localidade, pois apesar da implementação das políticas habitacionais municipais que ocorreram desde o início da formação do bairro, ainda há famílias que moram em barracos improvisados e em casas de taipa. Em contrapartida, pode-se verificar que a área se encontra em um processo de expansão que é fortemente influenciado pelo Programa Minha Casa, Minha Vida, que de acordo com a Lei 11.977/2009 tem por finalidade criar mecanismos de incentivo à produção e aquisição de novas unidades habitacionais ou requalificação de imóveis urbanos e produção ou reforma de habitações rurais, para famílias de baixa renda. A Figura 03 apresenta os registros fotográficos referentes ao déficit habitacional e a expansão do Bairro Manoel Deodato: 
Figura 3 - Casas de taipa e os avanços do Programa Minha Casa, Minha Vida no Bairro Manoel Deodato, em Pau dos Ferros/RN

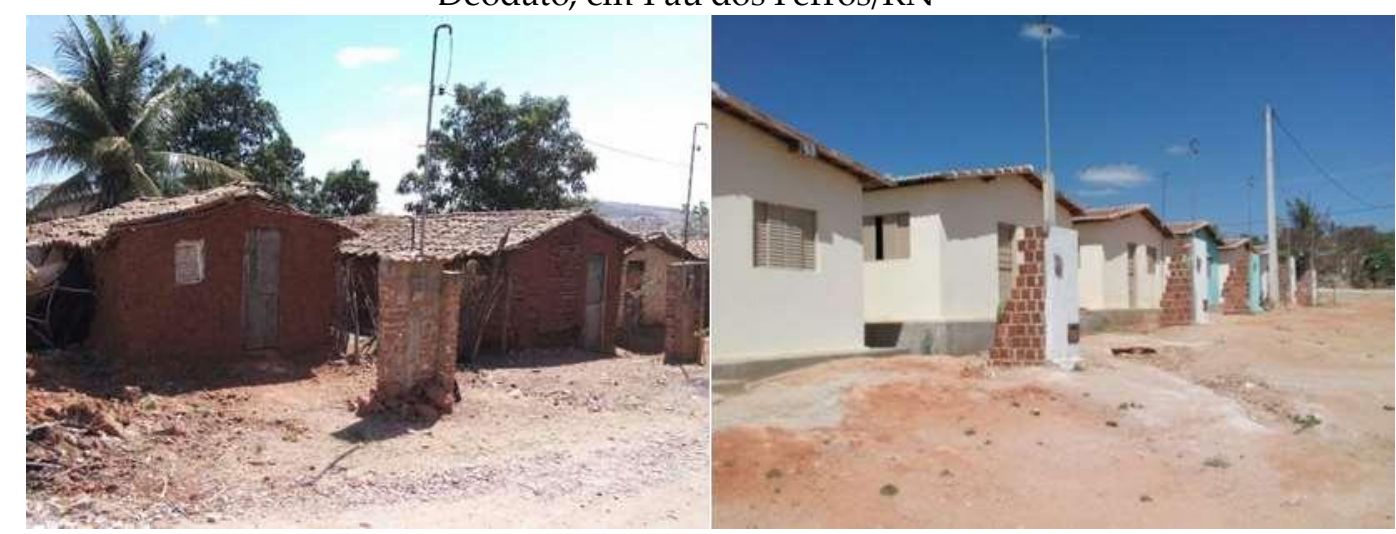

Fonte: Pesquisa, 2015

\section{Considerações Finais}

A segregação socioespacial é um problema presente no Brasil e esse, decorre das relações capitalistas, visto que o desenvolvimento econômico, bem como os avanços políticos e sociais ocorreram de forma desigual entre as regiões brasileiras, o que propiciou o surgimento das desigualdades nos mais diversos contextos. Entretanto, uma série de avanços no que se refere as políticas públicas contribuíram para a redução de tais desigualdades e proporcionaram a formação de novos centros urbanos, além da expansão das cidades intermediárias que atuam como um vínculo entre as pequenas e grandes cidades.

Entretanto, esse problema se encontra em menor dimensão nos pequenos e médios centros urbanos, visto que mesmo nesses ambientes as desigualdades referentes a ocupação do espaço e as interações sociais se mostram expressivas. Nesse contexto, a Cidade de Pau dos Ferros/RN tem a especulação imobiliária, juntamente com o desenvolvimento do comércio local como os principais agravantes no que se refere a segregação socioespacial.

Como fruto de todas essas interações, podemos apontar o Bairro Manoel Deodato, que por sua vez, possui marcas expressivas desse processo, visto que a população residente se apresenta vulnerabilidade econômica, há uma carência de infraestrutura e equipamentos urbanos, além da existência do déficit habitacional e de riscos ambientais.

\section{Referências}

BARREIRA, I. A. F. O ofício de ensinar para iniciantes: contribuições ao modo sociológico de pensar. 2014. Disponível em: <http://www.rcs.ufc.br/edicoes/v45n1/rcs_v45n1a3.pdf>. Acesso em: 11 nov. 2015.

BRASIL. Instituto Brasileiro de Geografia e Estatísticas. Regiões de Influência das Cidades. 2007. Disponível em: <http://www.mma.gov.br/estruturas/PZEE/_arquivos/regic_28.pdf>. Acesso em: 11 nov. 2015.

BRASIL. Instituto Brasileiro de Geografia e Estatísticas. Estimativas da população residente no Brasil e unidades da Federação com data de referência em $1^{\mathrm{o}}$ de julho de 2014 . Disponível em: <ftp://ftp.ibge.gov.br/Estimativas_de_Populacao/Estimativas_2014/estimativa_dou_2014.pdf>. Acesso em: 01 nov. 2014.

BRASIL. Instituto Brasileiro de Geografia e Estatística. Cidades. 2015. Disponível em: $<$ http://www.cidades.ibge.gov.br/xtras/perfil.php?lang=\&codmun=240940\&search=rio-grande-do- norte l paudos-ferros>. Acesso em: 11 nov. 2015.

BRASIL, Ministério das Cidades. Política Nacional de Desenvolvimento Urbano, 2004.

BRASIL, Instituto de Pesquisa Econômica Aplicada. Dinâmica Urbano-Regional: rede urbana e suas interfaces. Brasília: Ipea, 2011. 
BRASIL, Instituto de Pesquisa Econômica Aplicada. Estrutura produtiva avançada e regionalmente integrada: diagnóstico e políticas de redução das desigualdades regionais. Brasília: Ipea, 2010.

BRASIL, Instituto de Pesquisa Econômica Aplicada. Estimativa do Déficit Habitacional Brasileira (PNAD 20072012). Brasília: Ipea, 2013.

BRASIL. Lei № 12.608, de 10 de Abril de 2012. Disponível em:

<http://www.planalto.gov.br/ccivil_03/_Ato2011-2014/2012/Lei/L12608.htm>. Acesso em: 07 nov. 2015.

BRASIL. Lei № 11.977, de 07 de Julho de 2009. Disponível em: <http://www.planalto.gov.br/ccivil_03/_ato20072010/2009/lei/111977.htm>. Acesso em: 07 nov. 2015.

CALVETE, A. S. O PAPEL DAS CIDADES MÉDIAS NA URBANIZAÇÃO BRASILEIRA: UM ESTUDO DE CASO SOBRE A CIDADE DE PALHOÇA-SC. 2011. $59 \quad$ f. Monografia (Especialização) - Curso de Ciências Econômicas, Universidade Federal de Santa Catarina, Florianopólis, 2011. Disponível em: <http://tcc.bu.ufsc.br/Economia302598>. Acesso em: 11 nov. 2015.

CARVALHO, C. C. A.; BARBOSA, A. C. L. Produção do Espaço e Fragmentação Socioespacial em Pau dos Ferros: considerações sobre o Chico Cajá, Nações Unidas e Princesinha do Oeste. 2014.Disponível em: <https://drive.google.com/a/ufersa.edu.br/file/d/0B5REc7dTaf_wWjZQb0VsZ200MnM/view>. Acesso em: 11 nov. 2015.

CORRÊA, R. L. O Espaço Urbano. 3 Ed. São Paulo: Ática, 1995. Disponível em: <http://reverbe.net/cidades/wpcontent/uploads/2011/08/Oespaco-urbano.pdf>. Acesso em: 11 nov. 2015.

DANTAS, J. R. Q. A (Re) Organização Sócio-Espacial no RN e suas Implicações para Pau Dos Ferros. 2011. Disponível em: <http://www.joinpp.ufma.br/jornadas/joinpp2011/CdVjornada/JORNADA_EIXO_2011/QUESTAO_UR BANA_E_GESTAO_DAS_CIDADES/A_(RE)_ORGANIZACAO_SOCIOESPACIAL_NO_RN_E_SU AS_IMPLICACOES_PARA_PAU_DOS_FERROS.pdf>. Acesso em: 11 nov. 2015.

DANTAS, J. R. Q.; CLEMENTINO, M. L. M. THE ROLEOF INTERMEDIATE CITIESFOR REGIONAL DEVELOPMENT: a study from thesub-regional centers (Pau dos FerrosRN, Cajazeiras-PB andSousa-PB). Geo Uerj, Rio de Janeiro, v. 1, n. 24, p.228- 255, mar. 2013.

FELACIO, R. M. A Produção do Espaço: segregação e diferenciação socioespacial na cidade de Criciúma-SC. 2013. 163 f. Dissertação (Mestrado) - Curso de Curso de Mestrado do Programa de Pós- graduação em Geografia e Geociências. Universidade Federal de Santa Maria, Santa Maria, 2013. Disponível em: <http://w3.ufsm.br/ppggeo/images/dissertacoes/dissertacoes_2013/Dissertação Rafael Matos Felacio.pdf>. Acesso em: 11 nov. 2015.

FERRÃO, J.; HENRIQUES, E. B.; NEVES, A. O Repensar as cidades de média dimensão. In Análise Social. LisboaPT,v. XXIX, p. 1123-1147. 1994.

HARVEY, D. A Produção Capitalista do Espaço. São Paulo: Anablume, 2005. Disponível em:

<http://www.mom.arq.ufmg.br/mom/babel/textos/harvey-producao-capitalista-espaco.pdf>. Acesso em: 11 nov. 2015.

GIL, A. C. Como elaborar projetos de pesquisa. 4ed. São Paulo: Atlas, 2009.

MARICATO, E.; et al. Cidades Rebeldes: passe livre e as manifestações que tomaram as ruas do Brasil. 1ª Ed. São Paulo: Boitempo: Carta Maior, 2013. 